\title{
NEUROLOGICAL MANIFESTATIONS OF MAGNESIUM DEFICIENCY IN INFANTILE GASTRO-ENTERITIS AND MALNUTRITION
}

\author{
BY \\ E. H. BACK, R. D. MONTGOMERY* and E. E. WARD \\ From the Medical Research Council Tropical Metabolism Research Unit \\ and the Departments of Paediatrics and Pathology, University College of the West Indies, Jamaica
}

(RECEIVED FOR PUBLICATION AUGUST 15, 1961)

The syndrome of severe protein malnutrition in infants, complicated as it frequently is by refractory vomiting or frank gastro-enteritis, presents gross electrolyte disturbances. Most notable of these is potassium depletion and an accumulation of sodium (Hansen, 1956; Frenk, Metcoff, Gómez, Ramos-Galván, Cravioto and Antonowicz, 1957; Waterlow and Mendes, 1957). In addition, magnesium deficiency has recently been demonstrated (Montgomery, 1960, 1961).

Calcium-deficient tetany is occasionally seen, but less rarely neurological disturbances occur which are resistant to calcium therapy. These may take the form of generalized hypertonus with neck stiffness and carpopedal spasm, or of irregular muscle twitching, coarse tremors or generalized convulsions. They have usually been pre-terminal events in cases with grave electrolyte imbalance.

Five cases are presented in which these neurological disorders were shown to be associated with low levels of serum magnesium. In three cases calcium was given parenterally without effect, and in all cases magnesium therapy was followed by a remission. Two of the cases survived.

\section{Case Reports}

All cases had a recent history of diarrhoea and three were severely malnourished. Serum electrolyte values are summarized in the Table.

Case 1. An 8-month-old female weighing $4.6 \mathrm{~kg}$. presented with extensive oedema, anaemia (Hb $5 \cdot 1$ g./100 ml.), hepatomegaly and hypoproteinaemia (serum albumin 1.4 , globulin $1.9 \mathrm{~g} . / 100 \mathrm{ml}$.). On admission there was intermittent coarse tremor of the limbs and jaw. Twelve hours later generalized muscular hypertonus had developed, with mild carpopedal spasm. Calcium gluconate $(0 \cdot 3$ g.) was given intravenously

\footnotetext{
* Present address: Department of Experimental Medicine, University of Cambridge.
}

without any effect, and shortly afterwards status epilepticus developed. Ninety minutes after the calcium, magnesium sulphate $(0.3 \mathrm{~g}$.) was given intravenously, and within 30 seconds the convulsions had ceased and muscle tone had become flaccid as it had been on admission. The child yawned twice but remained conscious.

Within three hours muscle tone again increased markedly, and bilateral limb twitches developed into convulsions. These again responded promptly to intravenous magnesium sulphate $(0.5 \mathrm{~g}$.). There were no further nervous manifestations. A muscle biopsy on the fourth day showed a magnesium content of 9.6 $\mathrm{mEq}$ per kg. wet weight (normal 16-18 $\mathrm{mEq}$ ).

The child's general condition remained stationary for several days, but diarrhoea continued and jaundice became apparent on the seventh day. Treatment included blood transfusion, chloramphenicol, folic acid, vitamin $\mathrm{K}$ and oral albumin followed by a casilan mixture with added potassium and magnesium. Death occurred in coma on the tenth day with deep jaundice and purpura. Autopsy revealed an extremely fatty liver $(65 \%$ fat) and bronchopneumonia.

Case 2. A female aged 16 months weighed $5 \cdot 7 \mathrm{~kg}$. on admission. She was anaemic and dehydrated with mild oedema, moderate hepatomegaly, skin sepsis and severe weakness and apathy. Haemoglobin after rehydration was $5.0 \mathrm{~g} . / 100 \mathrm{ml}$. There was no diarrhoea, but she vomited intragastric feeds for five days, and continuous intravenous therapy was maintained, including blood, tetracycline and dextrose-plasma with added potassium. On the sixth day there was generalized muscle spasm, severe neck stiffness, and twitching of the extremities which became continuous and epileptiform, with loss of consciousness. Intravenous calcium gluconate $(0.25 \mathrm{~g}$.) produced no relief and was followed after 30 minutes by magnesium sulphate $(0.25 \mathrm{~g}$.). As there was no immediate response this dose was repeated 10 minutes later. Convulsions then ceased, although hypertonus and semicoma persisted. A lumbar puncture showed no abnormality of the cerebrospinal fluid.

Jaundice and increasing hepatomegaly developed the following day. Although she was maintained on intra- 
TABLE

SERUM ELECTROLYTE LEVELS (mEq/litre) IN INFANTS SHOWING NEUROLOGICAL DISTURBANCES

\begin{tabular}{|c|c|c|c|c|c|c|c|c|c|}
\hline Case No. & Time & & & $\mathbf{M g}$ & $\mathrm{Ca}$ & $\mathbf{N a}$ & $\mathbf{K}$ & $\mathrm{Cl}$ & $\mathrm{CO}_{2}$ \\
\hline $\begin{array}{l}1 \\
2 \\
3 \\
4 \\
5\end{array}$ & 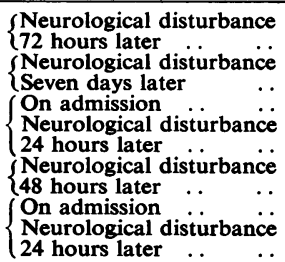 & $\begin{array}{l}\ldots \\
\cdots \\
\cdots \\
\cdots \\
\cdots \\
\cdots \\
\cdots \\
\cdots\end{array}$ & \begin{tabular}{l|}
$\cdots$ \\
$\cdots$ \\
$\cdots$ \\
$\cdots$ \\
$\cdots$ \\
$\cdots$ \\
$\cdots$ \\
$\cdots$ \\
$\cdots$ \\
$\cdots$
\end{tabular} & $\begin{array}{l}1 \cdot 23 \\
1 \cdot 95 \\
0 \cdot 78 \\
2 \cdot 25 \\
2 \cdot 10 \\
1 \cdot 00 \\
2 \cdot 50 \\
0 \cdot 83 \\
1 \cdot 70 \\
2 \cdot 00 \\
0 \cdot 80 \\
1 \cdot 75\end{array}$ & $\begin{array}{l}5 \cdot 1 \\
4 \cdot 1 \\
4 \cdot 9 \\
5 \cdot 5 \\
4 \cdot 7 \\
4 \cdot 7 \\
4 \cdot 6 \\
5 \cdot 5 \\
4 \cdot 8 \\
5 \cdot 1 \\
4 \cdot 8 \\
4 \cdot 9\end{array}$ & $\begin{array}{l}114 \\
114 \\
132 \\
136 \\
137 \\
161 \\
158 \\
140 \\
142 \\
120 \\
128 \\
140\end{array}$ & $\begin{array}{l}5 \cdot 1 \\
3 \cdot 8 \\
3 \cdot 8 \\
4 \cdot 1 \\
3 \cdot 2 \\
3 \cdot 1 \\
3 \cdot 1 \\
4 \cdot 5 \\
2 \cdot 4 \\
2 \cdot 0 \\
2 \cdot 5 \\
3 \cdot 2\end{array}$ & $\begin{array}{r}88 \\
80 \\
70 \\
86 \\
105 \\
109 \\
102 \\
105 \\
94 \\
80 \\
85 \\
80\end{array}$ & $\begin{array}{r}14 \\
15 \\
30 \\
26 \\
5 \\
15 \\
27 \\
5 \\
22 \\
29 \\
25 \\
30\end{array}$ \\
\hline
\end{tabular}

venous therapy she remained stuporose and died 11 days later with deep jaundice, melaena, pneumonia and uraemia.

Autopsy revealed an extremely fatty liver and bronchopneumonia.

Case 3. A well-nourished boy, age 1 year and weighing $9.3 \mathrm{~kg}$., had four days' history of fever and profuse diarrhoea. On admission he had a temperature of $104 \cdot 2^{\circ} \mathrm{F}$. $\left(40 \cdot 1^{\circ} \mathrm{C}\right.$.), and the respiratory rate was 72 . He was lethargic, grossly dehydrated and clinically acidotic. He was treated with intravenous fluids, receiving $500 \mathrm{ml}$. of one-sixth Molar lactate; after this he was clinically no longer acidotic. The drip was changed to $5 \%$ glucose in one-fifth normal saline, but after $100 \mathrm{ml}$. had been given the patient pulled the drip out. As he was taking oral feeds it was not replaced. He was given oral $5 \%$ dextrose in Darrow's solution and treated with tetracycline during the course of the day, but continued to have profuse watery stools. $\mathrm{He}$ again became grossly dehydrated and developed convulsions with groping movements on the right. The spinal fluid on lumbar puncture was normal. He was rehydrated with intravenous Hartman's solution and nursed in oxygen but continued to twitch, developing carpopedal spasm and a positive Cvostek's sign. The temperature rose to $106^{\circ} \mathrm{F}$. $\left(41 \cdot 1^{\circ} \mathrm{C}\right.$.). There was no improvement after the administration of calcium gluconate $1 \mathrm{~g}$. intravenously; twitchings continued with a peculiar high-pitched cry. He was then given an electrolyte solution containing magnesium $6 \mathrm{mEq}$ per litre. Following this the convulsions improved and the next day he was neurologically normal. Subsequent recovery was complete.

Case 4. This boy was 2 years of age. At the age of 14 months he had been admitted to hospital with gastroenteritis and malnutrition and his weight was $5 \mathrm{~kg}$. He had been discharged after six weeks and remained well until five hours before readmission when there was an onset of profuse diarrhoea accompanied by vomiting.

On examination he was adequately nourished (weight after hydration $10.5 \mathrm{~kg}$.). He was extremely dehydrated and clinically acidotic. The respiratory rate was 35 and the temperature $99.6^{\circ}$ F. $\left(37 \cdot 6^{\circ}\right.$ C. $)$. He was drowsy with up-turned eyes, but otherwise the nervous system -was normal. He was treated with intravenous Hartman's solution pending electrolyte results. After $100 \mathrm{ml}$. had been given generalized convulsions began, which responded immediately to intravenous injections of magnesium sulphate $(0.5 \mathrm{~g}$.). Intravenous fluids were continued. He was treated with streptomycin and made an uneventful recovery.

Case 5. This 13-month-old girl weighing $7 \mathrm{~kg}$. was admitted with two weeks' history of vomiting and diarrhoea. She had a poor dietary history and on admission showed depigmented hair, glossitis, 'kwashiorkor jowls' and gross hepatomegaly. Clinically, she was moderately dehydrated. Treatment was begun with oral fluids and chloramphenicol, but profuse diarrhoea continued necessitating intravenous fluids. Her condition remained poor despite intravenous electrolyte infusions and plasma. She continued to have diarrhoea and to vomit if fed by mouth. Two days after admission a stiff neck was noted, together with generalized muscle rigidity and slight twitching. Intravenous magnesium sulphate $(0.5 \mathrm{~g}$.) was given after which the stiffness and twitching ceased. Her general condition, however, deteriorated with increasing oedema and vomiting until death four days after admission. Autopsy showed a severe fatty liver, degenerative changes in the renal tubules and a moderate degree of bronchiolitis.

\section{Discussion}

There has been difficulty in defining the clinical features of magnesium deficiency owing to the coexistence of other biochemical disturbances. Magnesium-deficient tetany is well recognized as a natural disorder of cattle (Underwood, 1959) and as an entity in experimental animals (Orent, Kruse and McCollum, 1932; Barron, Brown and Pearson, 1949; Roine, Booth, Elvehjem and Hart, 1949). This adds weight to various reports of comparable disorders in man (Hirschfelder and Haury, 1934; Miller, 1944; Flink, Stutzman, Anderson, Konig and Fraser, 1954; Mader and Iseri, 1955; Harmon, 1956; Smith and Eliel, 1956; Potts and Roberts, 1958; Agna and Goldsmith, 1958; Randall, Rossmeisl and Bleifer, 1959; Vallee, Wacker and Ulmer, 
1960; Durlach and Lebrun, 1960; Fletcher, Henly, Sammons and Squire, 1960; Hanna, Harrison, MacIntyre and Fraser, 1960).

Not all of these authors described tetany in the accepted sense of increased neuromuscular excitability, and when they did so there was seldom clear evidence that magnesium deficiency was responsible (Lancet, 1960). Greenberg and Tufts (1938) found experimental evidence that the syndrome in animals differed from that of calcium deficiency, and was due to hyperexcitability at midbrain level rather than at the neuromuscular junction. Hanna et al. (1960) concluded that the 'pure' syndrome in man included epileptiform convulsions, ataxia, mental depression, and muscular weakness; they did not observe overt tetany, although a positive Cvostek's sign gave evidence of increased neural excitability. According to others, muscular rigidity, tremors and twitches, choreo-athetoid movements and various mental disturbances should be added to the list of features.

There seems to be no argument, therefore, that the brain may be directly involved, but the origin of the increased neuromuscular activity of some cases is still in doubt. Apparent discrepancies may be only of degree.

In our own cases there were widespread biochemical disturbances, but hypocalcaemia and alkalaemia have been excluded. The muscle twitches and convulsions were clinically indistinguishable from those of hypocalcaemic tetany, and carpopedal spasm was apparent in two cases. Muscle weakness and mental dullness were profound but were not clearly specific. The coarse tremors that were a striking feature of Case 1 might well have been of extrapyramidal origin. Similarly the severe generalized muscle rigidity and head retraction of Cases 2 and 5 are not incompatible with a brainstem disturbance.

The general picture in infants is very similar to that of calcium deficiency, but in magnesium deficiency there appears to be a greater tendency to this severe degree of muscle rigidity, the stiff neck suggestive of meningitis being uncommon in calcium deficiency.

Although parenteral magnesium salts may have a general hypnotic effect, the response in these cases appears clinically to be much more specific, and this is borne out by the specific nature of the serum electrolyte changes.

It must be emphasized that the syndrome is a very rare complication of gastro-enteritis, and although severe diarrhoea and preceding malnutrition may each play their part we do not understand all the factors which precipitate it. Not only is a depletion of tissue magnesium compatible with normal serum levels (Fitzgerald and Fourman, 1956; Montgomery, 1960), but, like Martin, Mehl and Wertman (1952), we have occasionally observed serum magnesium levels below $1 \mathrm{mEq}$ per litre in cases which showed no neurological disorder.

Experiments show that magnesium deficiency may have a profound effect on general cellular metabolism, and might indirectly affect other intracellular electrolytes (Ernster and Löw, 1955; Vitale, Nakamura and Hegsted, 1957). Although we have not detected any specific clinical effect of magnesium therapy outside the central nervous system, this might be due to the multiplicity of factors involved. Owing to efficient renal conservation, repletion of magnesium will begin as soon as bowel loss is checked and the dietary intake increases. However, the experience of Fletcher et al. (1960) suggests that in magnesium depletion due to intestinal malabsorption specific therapy may have a direct effect on the impaired intestinal function. The relative importance of intracellular magnesium in the function of various organs remains to be explored.

\section{Summary}

Five cases are described of infantile gastroenteritis in which neurological disturbances including tremor, muscle rigidity, twitches and convulsions were associated with low levels of serum magnesium. Three of the cases were frankly malnourished. Serum calcium levels were normal in all, and parenteral calcium was without therapeutic effect in three cases, whereas magnesium administration in all five cases induced remission of the neurological disorder.

The authors are indebted to Professor J. C. Waterlow for permission to report two of these cases.

\section{REFERENCES}

Agna, J. W. and Goldsmith, R. E. (1958). Primary hyperparathyroidism associated with hypomagnesemia. New Engl. J. Med., 258, 222.

Barron, G. P., Brown, S. O. and Pearson, P. B. (1949). Histological manifestations of magnesium deficiency in the rat and rabbit. Proc. Soc. exp. Biol., N. Y., 70, 220.

Durlach, J. and Lebrun, R. (1960). Importance de la forme hypomagnésienne de la spasmophilie. Ann. Endocr. (Paris), 21, 244.

Ernster, L. and Löw, H. (1955). Reconstruction of oxidative phosphorylation in aged mitochondrial systems. Exp. Cell Res., phosphorylation

Fitzgerald, M. G. and Fourman, P. (1956). An experimental study of magnesium deficiency in man. Clin. Sci., 15, 635 .

Fletcher, R. F., Henly, A. A., Sammons, H. G. and Squire, J. R (1960). A case of magnesium deficiency following massive intestinal resection. Lancet, $1,522$.

Flink, E. B., Stutzman, F. L., Anderson, A. R., Konig, T. and Fraser, R. (1954). Magnesium deficiency after prolonged parenteral fluid administration and after chronic alcoholism parenteral fluid administration and after chronic alcoholicated by delirium tremens. J. Lab. clin. Med., 43, 169.

complicated by delirium tremens. J. Lab. clin. Med., 43, 169.
Frenk, S., Metcoff, J., Gómez, F., Ramos-Galván. R., Cravioto, J. and Antonowicz, I. (1957). Intracellular composition and homeostatic mechanisms in severe chronic infantile malnutrition: II. Composition of tissues. Pediatrics, 20, 105.

Greenberg, D. M. and Tufts, E. V. (1938). The nature of magnesium tetany. Amer. J. Physiol., 121, 416. 
Hanna, S., Harrison, M., MacIntyre, I. and Fraser, R. (1960). The syndrome of magnesium deficiency in man. Lancet, 2, 172.

Hansen, J. D. L. (1956). Electrolyte and nitrogen metabolism in kwashiorkor. S. Afr. J. Lab. clin. Med., 2, 206.

Harmon, M. (1956). Parathyroid adenoma in a child: report of a case presenting as central nervous system disease and complicated by magnesium deficiency. Amer. J. Dis. Child. p1, 313 .

Hirschfelder, A. D. and Haury, V. G. (1934). Clinical manifestations of high and low magnesium: dangers of Epsom salt purgation in nephritis. J. Amer. med. Ass., 102, 1138.

Lancet (1960). Magnesium-deficient tetany in man (annotation). $1,1232$.

Mader, I. J. and Iseri, L. T. (1955). Spontaneous hypopotassemia, hypomagnesemia, alkalosis and tetany due to hypersecretion of corticosterone-like mineralocorticoid. Amer.J. Med., 19, 976.

Martin, H. E., Mehl, J. and Wertman, M. (1952). Symposium on recent advances in medicine: clinical studies of magnesium metabolism. Med. Clin. N. Amer., 36, 1157.

Miller, J. F. (1944). Tetany due to deficiency in magnesium: its occurrence in a child of 6 years with associated osteochondrosis of capital epiphysis of femur (L egg-Perthes Disease). Amer. J. Dis. Child., 67, 117

Montgomery, R. D. (1960). Magnesium metabolism in infantile protein malnutrition. Lancet, $2,74$.

(1961). Magnesium balance studies in marasmic kwashiorkor. J. Pediat., 59, 119.
Orent, E. R., Kruse, H. D. and McCollum, E. V. (1932). Studies on magnesium deficiency in animals: Species variation in symptomatology of magnesium deprivation. Amer. J. Physiol. $101,454$.

Potts, J. T. and Roberts, B. (1958). Clinical significance of magnesium deficiency and its relation to parathyroid disease. Amer. J. med. Sci., 235, 206.

Randall, R. E., Rossmeisl, E. C. and Bleifer, K. H. (1959). Magnesium depletion in man. Ann. intern. Med., 50, 257.

Roine, P., Booth, A. N., Elvehjem, C. A. and Hart, E. B. (1949) Importance of potassium and magnesium in nutrition of guinea pig. Proc. Soc. exp. Biol., N.Y., 71, 90.

Smith, W. O. and Eliel, L. P. (1956). Metabolic interrelations of calcium and magnesium in patients with and without osteolytic diseases. Clin. Res. Proc., 4, 245.

Underwood, E. J. (1959). Mineral metabolism. Ann. Rev. Biochem., 28, 499.

Vallee, B. L., Wacker, W. E. C. and Ulmer, D. D. (1960). The magnesium-deficiency tetany syndrome in man. New Engl. J. Med., 262, 155.

Vitale J. J., Nakamura, M. and Hegsted, D. M. (1957). Effect of magnesium deficiency on oxidative phosphorylation. J. biol. Chem., 228, 573.

Waterlow, J. C. and Mendes, C. B. (1957). Composition of muscle in malnourished human infants. Nature (Lond.), 180, 1361. 